\title{
A Zoospore Inoculation Method with Phytophthora sojae to Assess the Prophylactic Role of Silicon on Soybean Cultivars
}

Valérie Guérin and Amandine Lebreton, Département de Phytologie, Université Laval, Québec, QC, G1V 0A6, Canada; Erik E. Cogliati, Agroinnova, University of Turin, Via Leonardo da Vinci 44, 10095, Grugliasco (To), Italy; Sue E. Hartley, Department of Biology, University of York, York, YO10 5DD, UK; François Belzile, Département de Phytologie, Université Laval; James G. Menzies, Agriculture and Agri-food Canada, 101 Route 100, Morden, MB, R6M 1Y5, Canada; and Richard R. Bélanger, Département de Phytologie, Université Laval

\begin{abstract}
Guérin, V., Lebreton, A., Cogliati, E. E., Hartley, S. E., Belzile, F., Menzies, J. G., and Bélanger, R. R. 2014. A zoospore inoculation method with Phytophthora sojae to assess the prophylactic role of silicon on soybean cultivars. Plant Dis. 98:1632-1638.

The objective of this study was to evaluate whether silicon ( $\mathrm{Si}$ ) amendments, known to have a prophylactic role against biotrophic and hemibiotrophic pathogens, could protect soybean against Phytophthora sojae. To fulfill this objective, the initial challenge was to develop a method of inoculation that reproduced the natural infection process while allowing regular Si feeding to the plants. In a first set of experiments, inoculation of $P$. sojae zoospores directly into hydroponic solutions led to reproducible infections and expected phenotypes when using 'Williams' (rps), 'L75-6141' (Rps1a), 'haro15' (Rps1k), and 'L77-1863' (Rps 1b) soybean challenged to races 3 and 7 of $P$. sojae.

soybean cultivars against different races of $P$. sojae in a controlled environment, and the expression of partial and root resistance. In a second set of experiments aimed at testing the effect of $\mathrm{Si}$, our results clearly showed that $\mathrm{Si}$ amendments had a significant effect on disease reduction and plant yield. The effect was particularly noticeable when combined with a cultivar displaying a certain level of resistance to the disease. These results demonstrate a useful method of direct inoculation of soybean plants with $P$. sojae zoospores through a hydroponic system and show that $\mathrm{Si}$ amendments can represent an alternative method of control of $P$. sojae against soybean.
\end{abstract} This approach offers the advantage of testing simultaneously many
Phytophthora stem and root rot (PSR), caused by Phytophthora sojae Kaufm. \& Gerd. (syn. Phytophthora megasperma f. sp. glycines), is one of the most important and widespread diseases of soybean (22). P. sojae has a restricted host range, with soybean as its primary host (23). It affects plants at any stage from seedling to harvest and occurs when conditions of drainage are poor or when fields are subjected to flooding for an extended period (22). PSR causes significant losses in soybean yield each year worldwide (23). Different methods exist to reduce economic losses and these include seed treatments with metalaxyl-M (8) and the use of cultivars that carry single-gene resistance (Rps genes) or partial resistance by multiple genes $(6,18)$. Genetic resistance is usually specific to the race of the pathogen, which varies in each area of soybean production (11). Diseases caused by Phytophthora spp. are very difficult to control because they affect the underground parts of the plants, where fungicides have limited effect (23). The other complication is that oomycetes can rapidly adapt and overcome chemical control and genetic resistance (23).

Numerous studies have confirmed that the application of silicon (Si) to agricultural crops leads to several benefits, including the repression of many fungal diseases (9). For reasons still debated but possibly related to modulation of systemic acquired resistance (SAR), the prophylactic effects of Si seem to be more pronounced against biotrophic or hemibiotrophic pathogens $(9,10)$. Given that $P$. sojae is a hemibiotrophic organism, with a biotrophic phase early in its life cycle (15), we surmised that Si could potentially exert some form of control against this pathogen.

Corresponding author: R. Bélanger,

E-mail: richard.belanger@fsaa.ulaval.ca

Accepted for publication 16 May 2014.

http://dx.doi.org/10.1094/PDIS-01-14-0102-RE

(c) 2014 The American Phytopathological Society
Another particularity of Si applications is that plants, and even cultivars within a species, absorb the element to varying degrees and the plant's response to $\mathrm{Si}$ is correlated with their ability to absorb the element (12). Soybean is not a species known to accumulate large quantities of $\mathrm{Si}$, relative to plant families such as Poaceae, although some cultivars have been reported to accumulate well above $1 \%$ dry weight (1).

Therefore, we were interested in determining whether (i) Si had a prophylactic effect against $P$. sojae and (i) soybean cultivars differing in their ability to absorb Si also differed in their response to the Si treatment. For the latter, we were also interested in determining whether augmenting the ability of soybean to absorb Si through genetic transformation with heterologous known strong Si transporters could yield better results.

We had to overcome a technical challenge in order to properly evaluate the role of $\mathrm{Si}$ in the $P$. sojae-soybean interaction. Indeed, recommended bioassays with $P$. sojae are usually based on either the hypocotyl inoculation method that consists of making a wound in the hypocotyl of a plantlet and injecting mycelium or sporangia into the wound (4) or the inoculation of a microquantity of zoospores directly on the roots (18). Because the prophylactic role of $\mathrm{Si}$ manifests itself before penetration by the pathogen and when plants are constantly absorbing $\mathrm{Si}$, we could not rely on either method. Consequently, we had to develop a method based on zoospore inoculation that mimics natural infection of the roots.

The objectives of this study were to (i) develop a method of inoculation of $P$. sojae on soybean that does not involve plant injury and allows silicon feeding, (ii) assess whether silicon amendment can improve resistance in soybean against $P$. sojae, and (iii) evaluate whether the level of absorption of Si by different soybean cultivars or transgenic lines expressing strong $\mathrm{Si}$ transporters is correlated with resistance to $P$. sojae.

\section{Materials and Methods}

Inoculation of soybean with zoospores of $\boldsymbol{P}$. sojae. Plant material. For validation of the inoculation method, four different cultivars known for their phenotypic response to $P$. sojae were used: 
'Williams', a genotype without an Rps (resistance to P. sojae) gene; 'L75-6141' (Rps1a) a genotype with no resistance to races 3 and 7 of $P$. sojae; and two cultivars known for their resistance to races 3 and 7, 'Haro15' (Rps1k) and 'L77-1863' (Rps1b) (Table 1). Seed were germinated in plastic petri dishes $(150$ by $15 \mathrm{~mm})$ containing filter paper wetted with sterile distilled water. After 5 days, seedlings were transferred to $9-\mathrm{cm}$ pots filled with rockwool, at the rate of one seedling per pot, fitted into a hydroponic system. The plants were grown in a greenhouse maintained at 25 and $20^{\circ} \mathrm{C}$ with a relative humidity of $70 \%$ and a photoperiod of $14 \mathrm{~h}$ under a light intensity of $1,000 \mu \mathrm{M} / \mathrm{m}^{2} / \mathrm{s}$ within the photosynthetically active radiation (PAR) region.

Hydroponic system. For all experiments, plants were grown in a hydroponic system to facilitate zoospore dispersion and to control Si rate. Briefly, four units, each including a magnetic drive pump (950 liters/h), a 60-liter tank, and two plastic tunnels (Hydrobec), were used. The hydroponic system was set to immerse the roots in Hoagland solution for $15 \mathrm{~min}$ every $45 \mathrm{~min}$. The final concentration of each mineral in the basal solution was $\mathrm{KNO}_{3}(101 \mathrm{mg} / \mathrm{liter})$, $\mathrm{KCl}$ (221 mg/liter), $\mathrm{CaCl}_{2}$ (235 mg/liter), $\mathrm{K}_{2} \mathrm{HPO}_{4}$ (17 mg/liter), $\mathrm{MgSO}_{4} \cdot 7 \mathrm{H}_{2} \mathrm{O}(250 \mathrm{mg} / \mathrm{liter}), \mathrm{MgCl}_{2} \cdot 6 \mathrm{H}_{2} \mathrm{O}(145 \mathrm{mg} / \mathrm{liter}), \mathrm{H}_{3} \mathrm{BO}_{3}$ $(0.28 \mathrm{mg} /$ liter $), \mathrm{MnSO}_{4} \cdot \mathrm{H}_{2} \mathrm{O}(0.3 \mathrm{mg} /$ liter $), \mathrm{CuSO}_{4} \cdot 5 \mathrm{H}_{2} \mathrm{O}(0.2$ $\mathrm{mg} /$ liter $), \quad \mathrm{ZnSO}_{4} \cdot 7 \mathrm{H}_{2} \mathrm{O} \quad(0.2 \mathrm{mg} / \mathrm{liter}), \quad \mathrm{Na}_{2} \mathrm{MoO}_{4} \cdot 2 \mathrm{H}_{2} \mathrm{O} \quad(0.15$ $\mathrm{mg} /$ liter), $\mathrm{Co}\left(\mathrm{NO}_{3}\right)_{2} \cdot 6 \mathrm{H}_{2} \mathrm{O}(0.05 \mathrm{mg} / \mathrm{liter})$, and $\mathrm{Fe}$ as Fe-EDTA (40 $\mathrm{mg} / \mathrm{liter}$ ). The $\mathrm{pH}$ was adjusted to 6.2 with $4 \mathrm{~N} \mathrm{HCl}$.

Inoculation with $P$. sojae. $P$. sojae races 3 and 7 were obtained from Dr. Allen Xue from Agriculture and Agri-Food Canada in Ottawa. The cultures were maintained on clarified V8 agar medium at $21^{\circ} \mathrm{C}$. Production of zoospores was performed according to the method proposed by $\mathrm{Li}$ et al. (17). Both isolates were grown on clarified V8 agar medium for 1 week at $25^{\circ} \mathrm{C}$ in the dark. To induce sporangium production, active mycelial plugs were transferred in $15 \mathrm{ml}$ of a soil extract (10 $\mathrm{g}$ of Pro-Mix [Premier Tech] in 1 liter of distilled water, mixed for $10 \mathrm{~min}$ at room temperature, and centrifuged at $9,000 \times g$ for $20 \mathrm{~min}$; supernatant was filtered under vacuum through filter paper] into $9-\mathrm{cm}$ petri dishes and incubated at $25^{\circ} \mathrm{C}$ for 5 days under a constant fluorescent light. The fungal suspension was then placed in the dark at $15^{\circ} \mathrm{C}$ for $48 \mathrm{~h}$, then returned for 2 days at $25^{\circ} \mathrm{C}$ under fluorescent light, followed by 1 day at $15^{\circ} \mathrm{C}$ in darkness. Zoospores were released by placing the suspension at $4^{\circ} \mathrm{C}$ for $1 \mathrm{~h}$ followed by another hour at $25^{\circ} \mathrm{C}$. Zoospore concentration for each race was measured using a hemocytometer. Inoculation was performed by adding $200 \mathrm{ml}$ of a suspension $(2 \times$ $10^{5}$ zoospores $/ \mathrm{ml}$ ) of each race directly into the tank containing the hydroponic solution 2 weeks after the seedlings were transferred into the hydroponic system.

Effect of Si amendment on disease incidence. Hydroponic solution amended with $\mathrm{Si}$. Si-amended solution $(\mathrm{Si}+)$ was prepared as follows: soluble potassium silicate (Kasil \#6 [26.5\% $\left.\mathrm{SiO}_{2}\right]$; PQ Corporation) was added to the water first, at a final concentration of $1.7 \mathrm{mM} \mathrm{Si}$ (or $100 \mathrm{ppm} \mathrm{SiO}_{2}$ ); $\mathrm{pH}$ was adjusted to 6.2 with $4 \mathrm{~N}$ $\mathrm{HCl}$. The other salts (mentioned above) were added only after $\mathrm{pH}$ adjustment to avoid any precipitation. Potassium levels were adjusted with $\mathrm{KCl}$ in the standard solution $(\mathrm{Si}-)$ to compensate for the input of $\mathrm{K}$ from the Kasil \#6. Solutions were replaced every week. Seedlings newly integrated in the hydroponic system were fertilized with Hoagland solution for 1 week before Si fertilization.

Plant material. Proprietary 'Jack' seed were obtained from Syngenta and 'Hikmok sorip' seed were obtained from our own bank and used as controls because of their known properties (1). Transgenic material was prepared and produced at Syngenta Biotech Inc. Lsil genes from wheat ('TaLsi1', accession number HM803114.1) or horsetail ('EaLsi1', HE858197) were used. Production of transgenic soybean plants was accomplished using immature seed targets of Jack via Agrobacterium tumefaciens-mediated transformation, as described by Dawson et al. (WO08112044) (2), using a herbicide selection agent. Briefly, maturing soybean pods were harvested from greenhouse-grown plants, sterilized with diluted bleach solution, and rinsed with sterile water. Immature seed were then excised from seed pods and rinsed with sterile water briefly.
Explants were prepared from sterilized immature seed and infected with disarmed $A$. tumefaciens strain EHA101 (13) harboring binary vectors 19929 and 20067. Explants were incubated with Agrobacterium suspension for 60 to $240 \mathrm{~min}$. Excess A. tumefaciens suspension was then removed by aspiration and explants were moved to plates containing a nonselective co-culture medium. Explants were co-cultured with A. tumefaciens at $23^{\circ} \mathrm{C}$ for 4 days in the dark. Explants were then transferred to a recovery medium supplemented with an antibiotic mixture consisting of ticarcillin (75 $\mathrm{mg} / \mathrm{liter}$ ), cefotaxime (75 mg/liter), and vancomycin (75 mg/liter) and incubated in the dark for 7 days. Explants were then transferred to a regeneration medium containing a herbicide selection agent. Explants containing regenerated shoots were further transferred to elongation media containing a herbicide selection agent for shoot elongation and continued selection. When shoots were 3 to $5 \mathrm{~cm}$ long, they were transplanted to soil for rooting. Regenerated plantlets were tested for the presence of Si transporter genes and for the absence of a spectinomycin (spec) resistance gene present on the transformation vector backbone by TaqMan polymerase chain reaction (PCR) analysis (14). Transgenic plants were grown to maturity for seed production in a greenhouse.

Both genes integrated into the soybean genome were under the control of a root promoter, as proposed by Montpetit et al. (19).

Foliar Si concentration. The first trifoliate leaf of each plant was collected for $\mathrm{Si}$ concentration analysis 3 weeks after the first $\mathrm{Si}$ amendment. Dried leaves were ground to a powder in a bead homogenizer (Omni Bead Ruptor; Omni International). Measurements were made with a portable X-ray fluorescence spectrometer (Niton XL3t900 GOLDD XRF analyzer; Thermo Scientific) at the University of York, United Kingdom, according to the methods of Reidinger et al. (20). The Si rate assay was carried out with noninoculated plants.

Disease assessment. Disease assessment was made based on a scale from 0 to 4 , where 0 means no canker on the stem and 4 indicates expanded canker leading to plant death. Observations were made every other day following the appearance of the first symptoms at day 7. Disease was assessed for 35 days following inoculation. A mean was calculated each assessing day with values for each cultivar or line from both $\mathrm{Si}-$ and $\mathrm{Si}+$ treatments and was used to plot disease progress curve. To compare disease evolution among the treatments, the area under the disease progress curve (AUDPC) was calculated as:

$$
\text { AUDPC }=\sum_{i=1}^{n-1}\left[\left(y_{i}+y_{i+1}\right) \div 2\right]\left(t_{i+1}-t_{i}\right)
$$

where $y_{i}=$ stem rot severity at the $i$ th observation, $t_{i}=$ time (days), and $n=$ total number of observations (21).

Dry weight. At the end of each trial, aerial parts of each plant were harvested, placed in paper bags, and dried at $60^{\circ} \mathrm{C}$ for 2 days. Dry weight of each plant was noted and compared for each cultivar or line and treatment.

Experimental design and statistical analysis. For validation of the inoculation procedure, four plants, randomly distributed, were used for each cultivar and four more were used for noninoculated controls. For the effects of $\mathrm{Si}$, four plants for each cultivar and eight plants for each transgenic line (TaLsi1 and EaLsi1) were used for each treatment $(\mathrm{Si}-$ and $\mathrm{Si}+$ ). The experiment was replicated three times and data were pooled together. The cultivars or lines were totally randomized in a split-plot experimental design, with $\mathrm{Si}$ treatments as the main plot ( 0 and $1.7 \mathrm{mM} \mathrm{Si})$ and cultivars or lines as subplots. For each variable tested (silicon content in plant

Table 1. Soybean cultivars used for the validation of the inoculation method originating from Agriculture and Agri-Food Canada in Ottawa

\begin{tabular}{llll}
\hline Rps gene & Cultivar & Background & Source of Rps gene \\
\hline rps & Williams & Williams & $\ldots$ \\
Rpsla & L75-6141 & Williams & Union \\
Rps1b & L77-1863 & Williams & Harrell \\
Rps 1k & Haro15 & Harosoy & Kingwa \\
\hline
\end{tabular}


leaves, AUDPC, and dry weight), analysis of variance was performed using JMP software (SAS Institute Inc.). Least square means were used to express the results. Standard error was used as the error bar in figures.

\section{Results}

Inoculation of soybean with zoospores of $P$. sojae. First, a study was undertaken to evaluate the reliability of the inoculation method. Following addition of zoospores to the nutrient solution, plants were observed daily for the presence of symptoms. Root browning and stunting appeared as early as 6 days after inoculation (Fig. 1A) in susceptible Williams (rps) and L75-6141 (Rps1a). Symptoms progressed steadily and the first clear presence of cankers was noted 2 weeks after inoculation on the same susceptible cultivars (Fig. 1B). After 3 weeks, susceptible plants had a pronounced decayed root system and cankers extended from the base well into the stem of the plant (Fig. 1C). After 5 weeks, most plants in susceptible varieties showed limited root development and
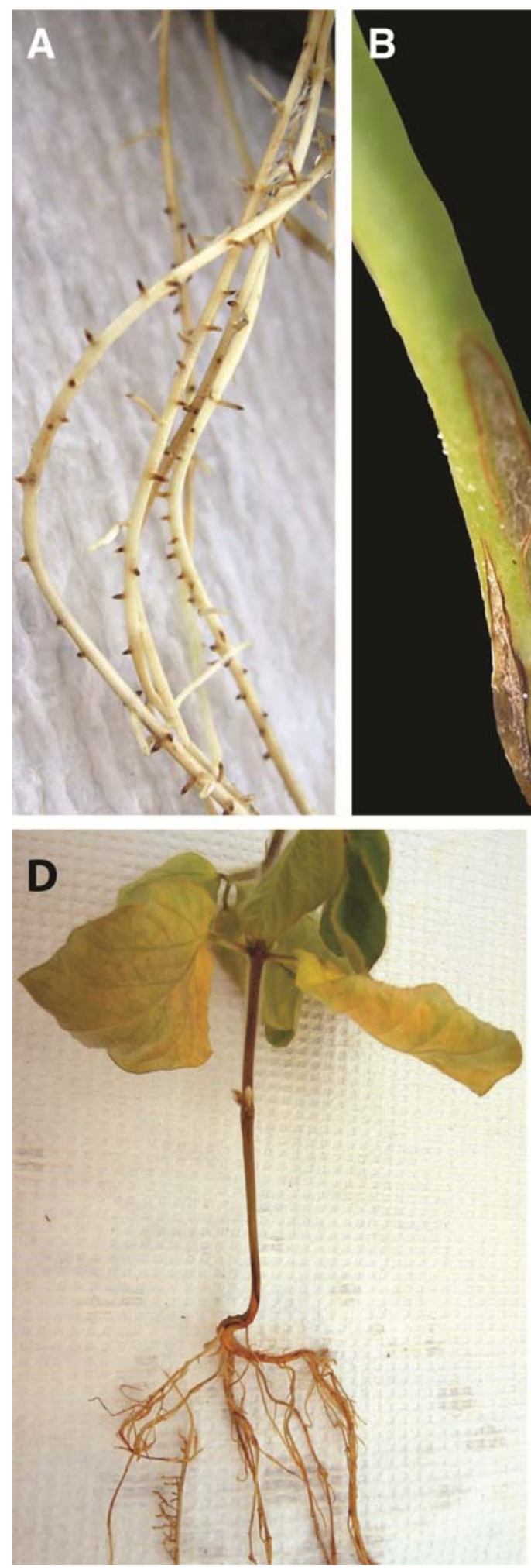
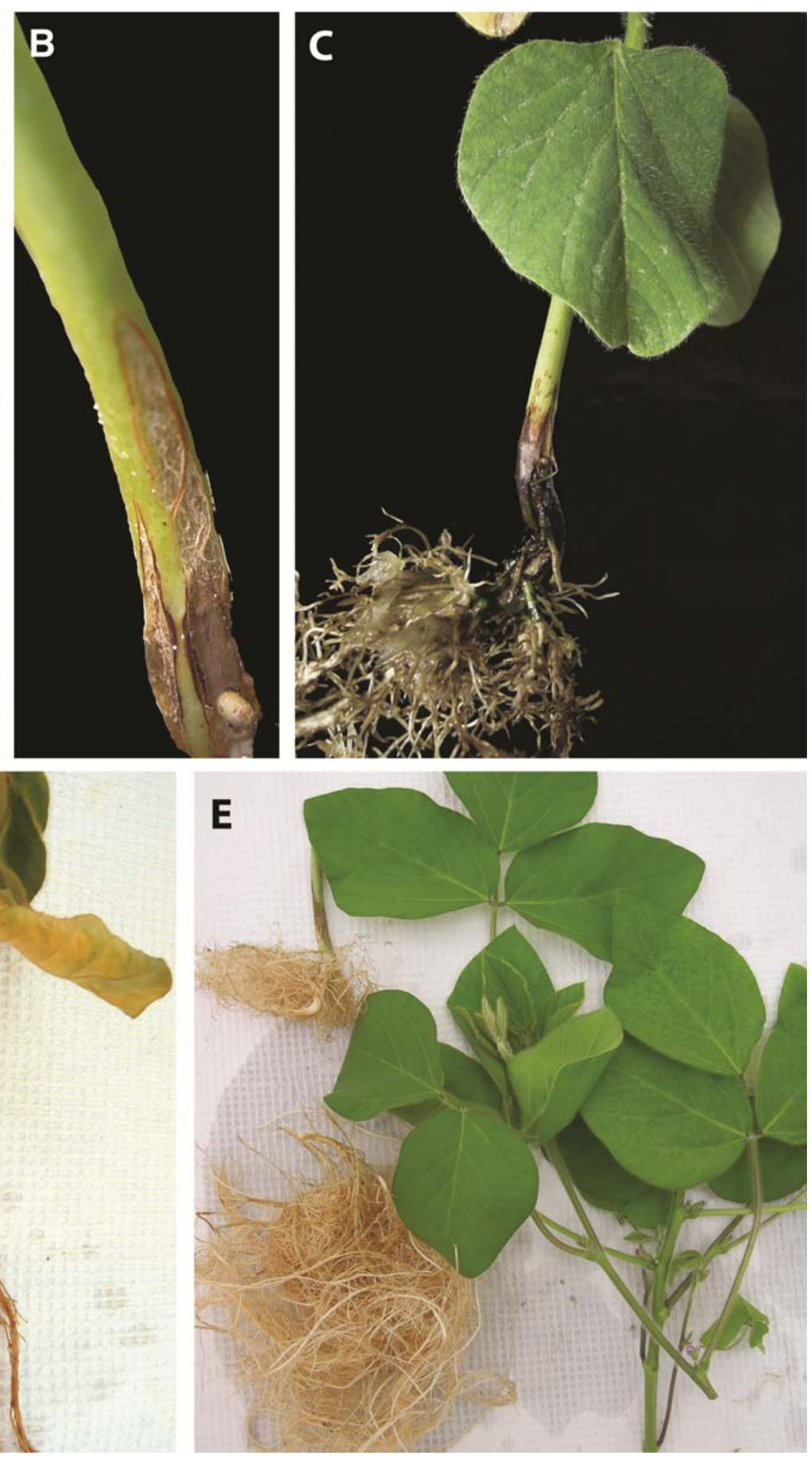

Fig. 1. Disease evolution of soybean plants grown in a hydroponic system and inoculated with Phytophthora sojae zoospores. A, Root browning; B, early stem lesion; C, advanced stem canker and root rot; typical phenotype on $\mathbf{D}$, a susceptible cultivar and $\mathbf{E}$, a resistant cultivar 35 days postinoculation. 
symptoms of wilting (Fig. 1D). As expected, plants from resistant material showed no visible symptoms of infection and displayed a fully developed root system after 5 weeks (Fig. 1E). At the end of the experiments, inoculated plants from susceptible Williams and

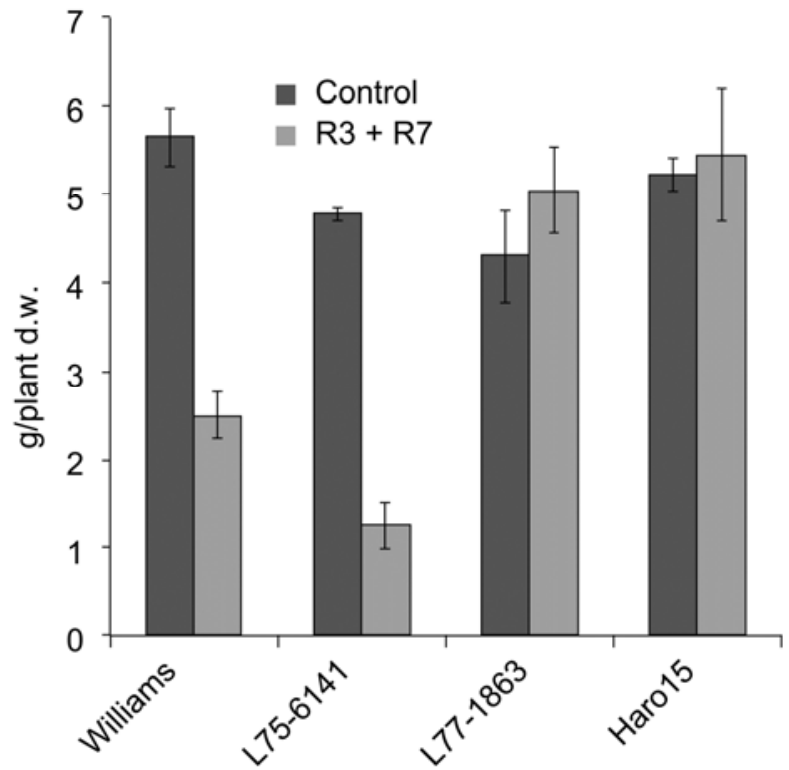

Fig. 2. Shoot dry weight of Williams ( $r p s)$, a susceptible cultivar; L75-6141 (Rps1a), a genotype with no resistance to races 3 and 7 of Phytophthora sojae; and L771863 (Rps1b) and Haro15 (Rps1k), two cultivars known for their resistance to races 3 and 7 grown in a hydroponic system 35 days after inoculation with zoospores of Phytophthora sojae races 3 and $7 ; n=4$. Analysis of variance significant $(P<$ 0.0001); error bars $=$ standard error.
L75-6141 had significantly less dry weight than their noninoculated counterpart (Fig. 2). For their part, inoculated plants from resistant Haro15 and L77-1863 had similar dry weights as their respective control plants (Fig. 2).

Effect of Si amendment on disease incidence. Following the validation of the expected phenotypic response of different soybean cultivars with zoospore inoculation in the hydroponic system, we wanted to evaluate the effects of Si amendments on PSR in different cultivars or transgenic lines of soybean. The first disease symptoms were observed on roots 7 days after addition of $P$. sojae zoospores in the nutrient solution. Whether they were treated or not with $\mathrm{Si}$, all plants showed early symptoms of root discoloration. However, as time progressed, symptoms of wilting and presence of cankers were more visible on plants that were not treated with Si (Figs. 1B and 3). At the end of the experiment (day 35), the prophylactic effect of $\mathrm{Si}$ against $P$. sojae was observed on all plants from lines TaLsi1, EaLsi1, and Hikmok sorip (Fig. 4A-C). One notable exception was observed with Jack, known for its high level of partial resistance to PSR (17), which showed little disease regardless of the $\mathrm{Si}$ treatment compared with the other cultivars (Fig. 4D). Considering that the transgenic lines were produced from Jack material, it was somewhat surprising that those lines showed higher susceptibility to $P$. sojae than Jack.

When disease was assessed on the basis of AUDPC, $\mathrm{Si}+$ plants from both transgenic lines and Hikmok sorip had significantly lower AUDPC values than $\mathrm{Si}-$ plants (Fig. 5). Si- plants from Hikmok sorip were by far the most susceptible, with more than twice the AUDPC values than those of EaLsi1 and TaLsi1 plants. Plants from Jack displayed a high level of resistance to the disease that nullified the effect of Si. On the other hand, the AUDPC value was reduced on lines TaLsil and EaLsil supplied with $\mathrm{Si}$ to the same level observed on plants of Jack. Si+ plants of Hikmok sorip had a
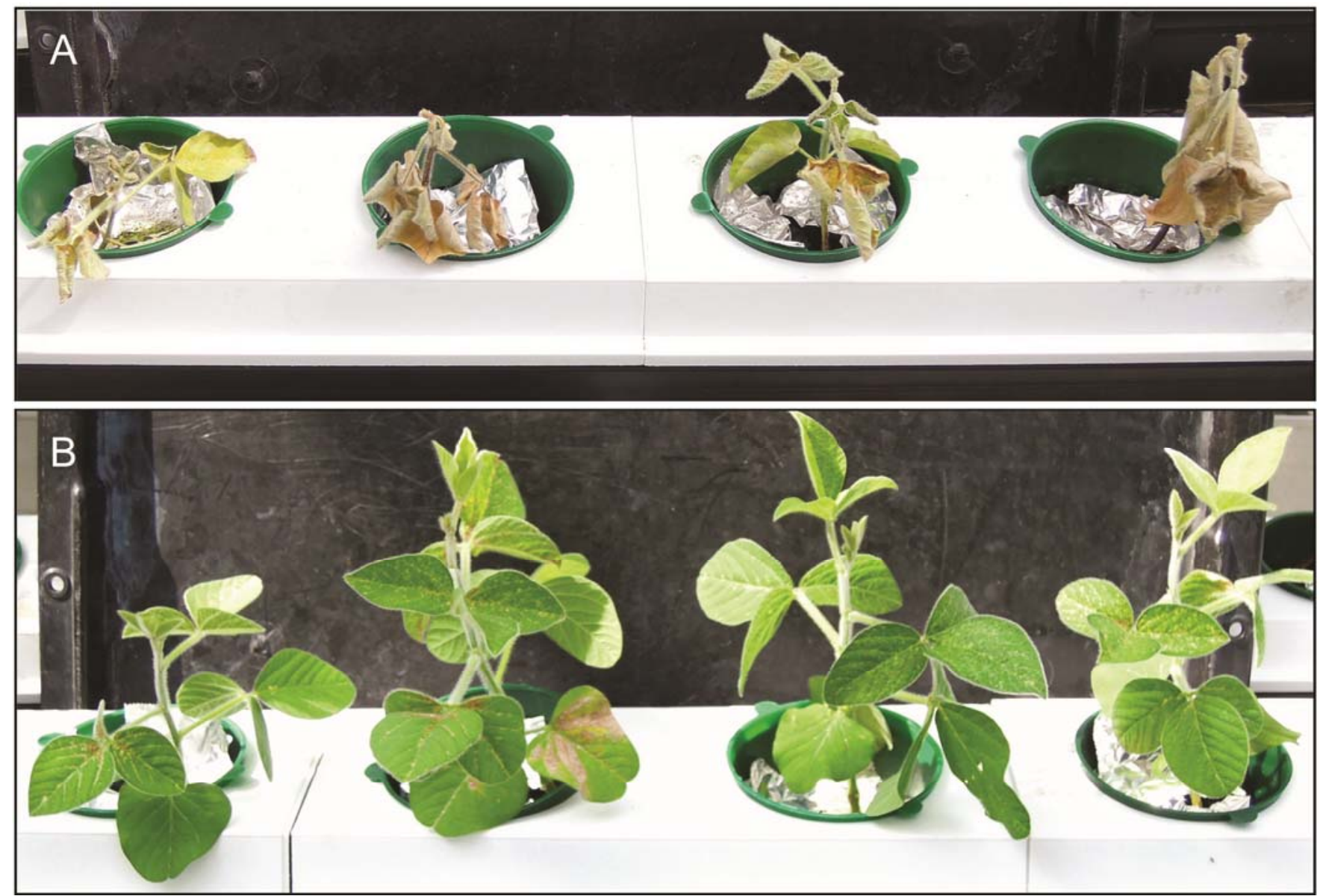

Fig. 3. Soybean plants infected with Phytophthora sojae 35 days after infection in $\mathbf{A}$, a control or $\mathbf{B}$, a silicon-amended solution (1.7 mM). 
higher AUDPC value than all other plants but the Si treatment still reduced the AUDPC value by more than 16 points.

Dry weight. After 35 days, all inoculated plants from EaLsi1, TaLsi1, and Hikmok sorip receiving the Si treatment had a significantly higher dry weight than plants not treated with Si (Fig. 6). There was no significant difference between plants of Jack.

Foliar Si concentration. When plants were measured for $\mathrm{Si}$ content, Hikmok sorip plants fed with Si contained significantly more $\mathrm{Si}$, exceeding by more than twice the concentration found in all other cultivars (Fig. 7). Surprisingly, transgenic lines containing an Si transporter from either wheat or horsetail did not accumulate more Si than Jack plants. Expectedly, plants grown without Si amendments contained significantly less $\mathrm{Si}$ and there was no difference among the cultivars (Fig. 7).

\section{Discussion}

We describe an inoculation method of soybean with $P$. sojae that relies exclusively on zoospores added to a hydroponic solution. This methodology induced infections that reflected accurately the expected phenotypes on cultivars with known resistance to $P$. sojae and allowed evaluation of the prophylactic effect that $\mathrm{Si}$ amendments could have against the disease on soybean.

$\mathrm{Si}$ is well known for its protective effect against many fungal pathogens and is particularly effective against biotrophs by mediating physical and induced resistance preventing pathogen penetration into the plant tissue (9). P. sojae is described as a hemibiotroph (15) and can either penetrate directly into the root cortex and form haustoria into root cells (7) or penetrate by a wound and act as a necrotroph. The standard inoculation method, consisting of injecting mycelium into a wound in the hypocotyl of the plantlet (4), was inadequate for our purposes because it bypasses the biotrophic phase with which $\mathrm{Si}$ interferes. By adding zoospores directly into a hydroponic solution, we were able to obtain a homogenous inoculation procedure that led to reproducible infection

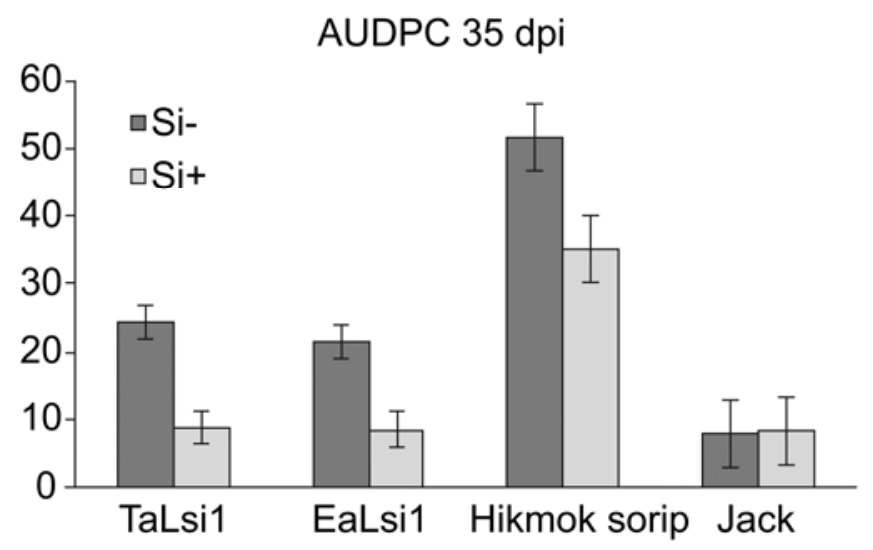

Fig. 5. Phytophthora stem and root rot incidence expressed as area under disease progress curve (AUDPC) on soybean plants fed with a control or silicon (Si)amended solution (1.7 mM Si [Si+]) over 35 days following inoculation. Analysis of variance was performed on a full factorial experiment (four lines by two treatments by three replications; $n=12$ for Hikmok sorip and Jack and $n=24$ for TaLsi1 and EaLsi1). Differences were significant between the lines $(P<0.0001)$ and the $\mathrm{Si}$ treatment $(P<0.0001)$. Error bar $=$ standard error.
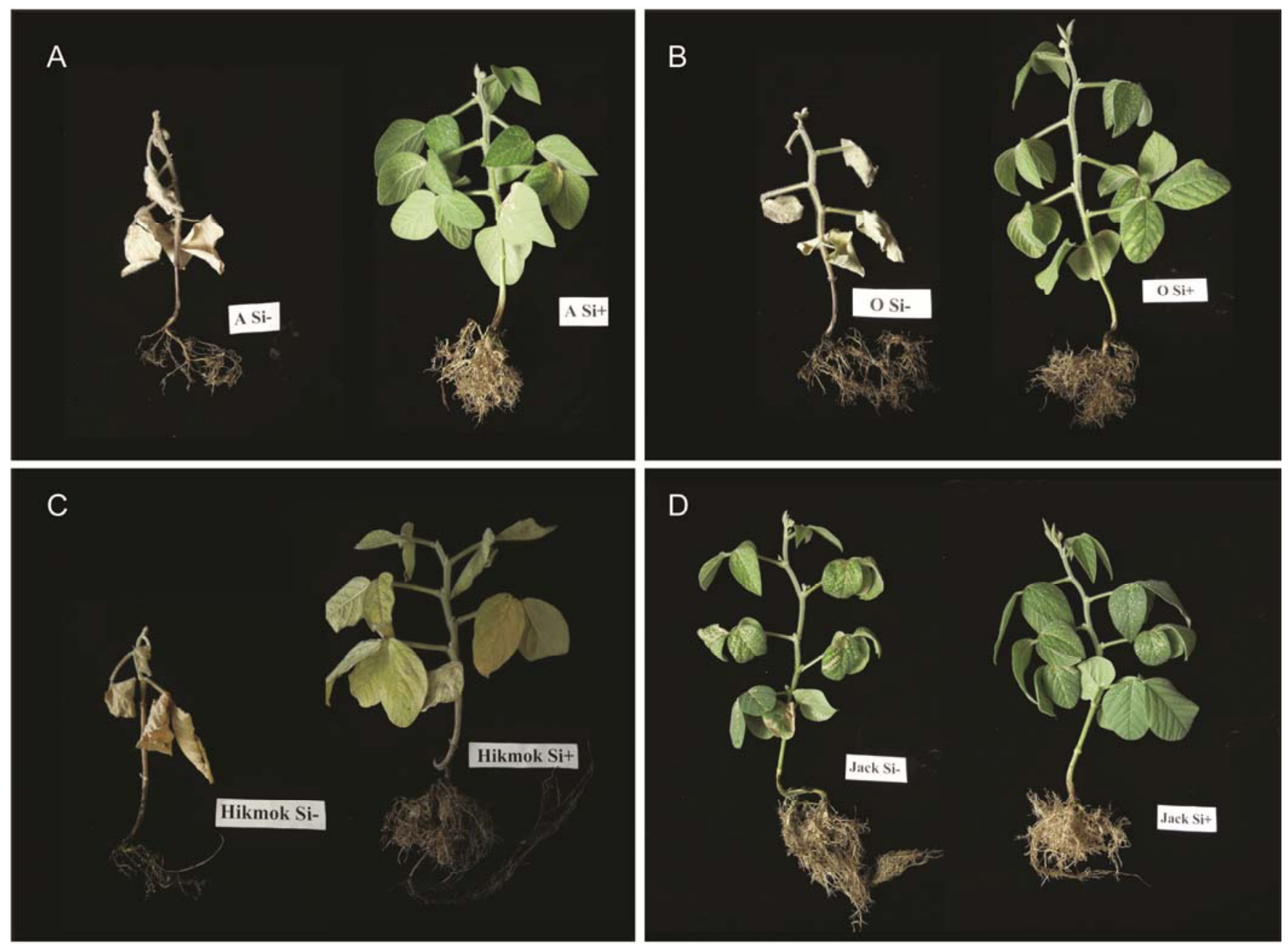

Fig. 4. Effect of silicon amendment on plants infected by Phytophthora sojae 35 days post-infection. A, TaLsi1 transgenic line; B, EaLsi1 transgenic line; C, Hikmok sorip; and D, Jack. 
of plants. While, admittedly, the procedure is more cumbersome than the hypocotyl inoculation, it does offer a number of advantages. Indeed, the method has reliably detected the expected phenotypic response of cultivars with varying degrees of resistance to races 3 and 7 of $P$. sojae within the confine of a single inoculation. Moreover, it could allow the evaluation of partial resistance or root resistance and the expression of Rps2 genes inherent to the root system, a response bypassed with the hypocotyl inoculation (5). The method also offers the advantage of monitoring disease progress on the roots because plants can easily be removed from the system for observation and replaced without damaging the roots. Another advantage is the possibility of testing simultaneously several races of $P$. sojae against different soybean cultivars. The hydroponic system also reproduces optimal conditions for $P$. sojae development and avoids biases that soil or substrates could impose on zoospores. Finally, in the context of our objectives, the approach was perfectly suited to evaluate the effect of Si amendments, or any other amendments, on the incidence of $P$. sojae on soybean.

Our observations established, for the first time, that $\mathrm{Si}$ amendments to soybean plants have a prophylactic effect against $P$. sojae. The differences between Si-treated and untreated plants were striking and easily comparable with the hydroponic system. As in trials against Asian soybean rust (Phakopsora pachyrhizi) (1), Hikmok sorip was more susceptible to the disease than the other soybean lines. Considering this high level of infection, disease reduction afforded by $\mathrm{Si}$ was still significant. This is all the more relevant when one looks at results obtained with lines TaLsi1 and EaLsi1. Both control transgenic lines had a level of infection half of that observed with Hikmok sorip but the addition of Si reduced it to the lowest level, indicating that the protective effect of $\mathrm{Si}$ could be even more evident under moderate disease pressure or with material expressing only partial resistance. Expectedly, plants from Jack presented the typical response that is generally conferred by genetic partial resistance (18). Indeed, those plants were the least susceptible to races 3 and 7 of Phytophthora sojae, although they did not display the total resistant phenotype observed with Haro15 and L77-1863 tested in the first part of the study. As described by Dorrance et al. (7), damage is often limited to the roots in soybeans cultivars with partial resistance to $P$. sojae, which is what was observed on Jack plants. Given the limited infection on control plants, Si amendments did not confer an additional benefit. The higher resistance of Jack plants compared with plants from lines TaLsi1 and EaLsi1 was unexpected because the latter had theoretically the same genetic background as Jack. On the one hand, the inoculation method confirmed the expected phenotype for Jack (18) but, on the other hand, the proprietary seed material used for transformation

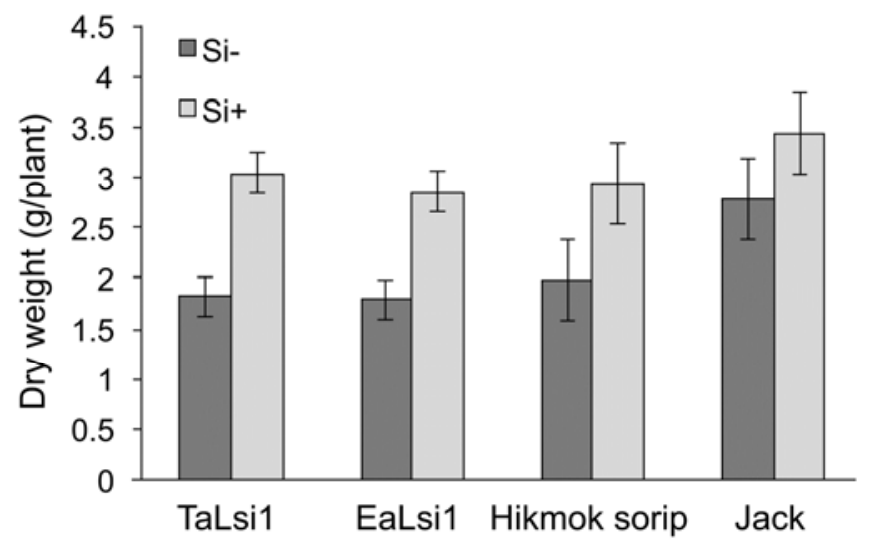

Fig. 6. Shoot dry weight of soybean plants inoculated with Phytophthora sojae and grown in control (Si-) or silicon-amended solution (1.7 mM Si [Si+]). Analysis of variance was performed on a full factorial experiment (four lines by two treatments by three replications; $n=12$ for Hikmok sorip and Jack and $2 n=4$ for TaLsi1 and EaLsi1). The effect of $\mathrm{Si}$ amendment was significant with $P<0.0001$; the effect of line (cultivar) was not significant with $P=0.1227$. Error bar $=$ standard error. may have been genetically different from Jack seed in its resistance to $P$. sojae or the transformation event may have altered its resistance background.

In line with disease results, dry weight measurements confirmed that the lesser infection levels on $\mathrm{Si}$ + plants translated into less growth reduction. $\mathrm{Si}+$ plants from all cultivars or lines tested had similar weight regardless of the infection level at the end of the experiment, suggesting that $\mathrm{Si}$ had reduced the negative impact of $P$. sojae on plant growth better than what was reflected by the disease scale.

Based on previous reports correlating high $\mathrm{Si}$ absorption with a better prophylactic effect, we wanted to compare plant material with a different genetic predisposition to absorb Si. Based on field data, soybean was considered to be a species with low affinity for $\mathrm{Si}$ absorption (12). For this reason, we hypothesized that the addition of heterologous Si influx transporters (Lsi1) into soybean plants would lead to increased Si absorption and, thus, increased disease protection. Therefore, we were surprised to observe that soybean plants transformed with Lsil transporters from species with high affinity for $\mathrm{Si}$ (wheat and horsetail) did not absorb more Si than control plants and absorbed significantly less than Hikmok sorip. This apparent contradiction was partially resolved in a very recent study by Deshmukh et al. (3), who described the presence of native Lsi1 transporters in soybean. The authors concluded that all soybean germplasm had the genetic predisposition to absorb $\mathrm{Si}$ through Lsi1 transporters, thus rendering the additional presence of heterologous transporters redundant and without benefit, as observed in our work.

Although this work was conducted in strictly confined conditions, it suggests that soil amendments with $\mathrm{Si}$ solutions or $\mathrm{Si}$ based fertilizers may confer benefits to soybean against $P$. sojae and other stresses. Incidentally, a recent study has shown that soil $\mathrm{Si}$ treatments reduced soybean rust incidence under field conditions (16).

In conclusion, this study describes an original inoculation procedure based on zoospore inoculation of hydroponic solution to test the resistance of soybean cultivars against Phytophthora sojae. This method expands the limits of the standard hypocotyl inoculation procedure by allowing simultaneous evaluation of different soybean cultivars and $P$. sojae races, expression of root resistance, and optimal conditions for $P$. sojae development leading to reproducible infections. By using this procedure, we were able to demonstrate the prophylactic role of Si against $P$. sojae. On the basis of our results, the combination of resistant or partially resistant soybean germplasm with $\mathrm{Si}$ amendments would offer a potential method to manage Phytophthora stem and root rot.

\section{Acknowledgments}

This work was supported by grants from Syngenta Canada, the Natural Sciences and Engineering Research Council of Canada, and the Canada Research

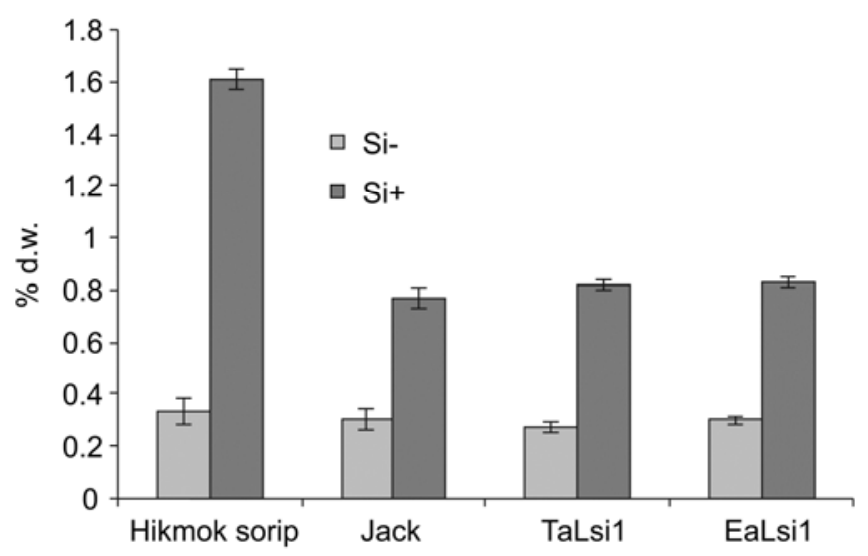

Fig. 7. Silicon (Si) concentration in shoots of soybean plants grown in a Si-free or Si-amended solution (1.7 mM Si). Analysis of variance was significant with $P=$ $0.0074 ; n=4$; d.w. = dry weight. Error bar = standard error. 
Chairs Program. We thank C. Labbé and G. Arsenault-Labrecque for technical assistance, J. Martin for help with silicon dosage, and A. Xue from Agriculture and Agri-food Canada for cultivars of soybean of the first part of the study and $P$. sojae cultures.

\section{Literature Cited}

1. Arsenault-Labrecque, G., Menzies, J. G., and Bélanger, R. R. 2012. Effect of silicon absorption on soybean resistance to Phakopsora pachyrhizi in different cultivars. Plant Dis. 96:37-42.

2. Dawson, J., Hwang, Y. -J., Que, Q., and Sigareva, M., 2008. Transformation of immature soybean seeds through organogenesis. WO Patent. App. PCT/US2008/000,956.

3. Deshmukh, R. K., Vivancos, J., Guérin, V., Sonah, H., Labbé, C., Belzile, F., and Bélanger, R. R. 2013. Identification and functional characterization of silicon transporters in soybean using comparative genomics of major intrinsic proteins in Arabidopsis and rice. Plant Mol. Biol. 83:303-315.

4. Dorrance, A. E., Berry, S. A., Anderson, T. R., and Meharg, C. 2008. Isolation, storage, pathotype characterization, and evaluation of resistance for Phytophthora sojae in soybean. Plant Health Prog. Online publication. doi:10.1094/PHP-2008-0118-01-DG

5. Dorrance, A. E., Jia, H., and Abney, T. S. 2004. Evaluation of soybean differentials for their interaction with Phytophthora sojae. Plant Health Prog. Online publication. doi:10.1094/PHP-2004-0309-01-RS

6. Dorrance, A. E., McClure, S. A., and St-Martin, S. K. 2003. Effect of partial resistance on Phytophthora stem rot incidence and yield of soybean in Ohio. Plant Dis. 87:308-312.

7. Dorrance, A. E., Mills, D., Robertson, A. E., Draper, M. A., Giesler, L., and Tenuta, A. 2007. Phytophthora root and stem rot of soybean. Plant Health Instructor. Online publication. doi:10.1094/PHI-I-2007-0830-07

8. Dorrance, A. E., Robertson, A. E., Cianzo, S., Giesler, L. J., Grau, C. R., Draper, M. A., Tenuta, A. U., and Anderson, T. R. 2009. Integrated management strategies for Phytophthora sojae combining host resistance and seed treatments. Plant Dis. 93:875-882.

9. Fauteux, F., Rémus-Borel, W., Menzies, J. G., and Bélanger, R. R. 2005. Silicon and plant disease resistance against pathogenic fungi. FEMS Microbiol. Lett. 249:1-6.

10. Fawe, A., Menzies, J. G., Chérif, M., and Bélanger, R. R. 2001. Silicon and disease resistance in dicotyledons. Pages 159-169 in: Studies in Plant Science 8, Silicon in Agriculture. L. E. Datnoff, G. H. Snyder, and G. H. Korndörfer, eds. Elsevier Science, New York.

11. Grau, C. R., Dorrance, A. E., Bond, J., and Russin, J. S. 2004. Fungal diseases. Pages 679-763 in: Soybeans: Improvement, Production and Uses. 3rd ed. Agron. Monogr. H. R. Boerma and J. E. Specht, eds. American Society of Agronomy, Madison, WI

12. Hodson, M. J., White, P. J., Mead, A., and Broadley, M. R. 2005. Phylogenetic variation in the silicon composition of plants. Ann. Bot. 96:10271046.

13. Hood, E. E., Helmer, G. L, Fraley, R. T., and Chilton, M. D. 1986. The hypervirulence of Agrobacterium tumefaciens A281 is encoded in a region of pTiBo542 outside of T-DNA. J. Bacteriol. 168:1291-1301.

14. Ingham, D. J., Beer, S., Money, S., and Hansen, G. 2001. Quantitative realtime PCR assay for determining transgene copy number in transformed plants. Biotechniques 31:132-140.

15. Lee, S. -J., and Rose, J. K. C. 2010. Mediation of the transition from biotrophy to necrotrophy in hemibiotrophic plant pathogens by secreted effector proteins. Plant Signal. Behav. 5:769-772.

16. Lemes, E., Mackowiak, C. L., Blount, A., Marois, J. J., Wright, D. L., Coelho, L., and Datnoff, L. E. 2011. Effects of silicon applications on soybean rust development under greenhouse and field conditions. Plant Dis. 95:317324.

17. Li, Y., Minerdi, D., Garibaldi, A., and Gullino, M. L. 2009. Molecular detection of Phytophthora cryptogea on Calendula officinalis and Gerbera jamesonii artificially inoculated with zoospores. J. Phytopathol. 157:438 445.

18. Mideros, S., Mizuho, N., and Dorrance, A. E. 2007. Characterization of components of partial resistance, Rps 2, and root resistance to Phytophthora sojae in soybean. Phytopathology 97:655-662.

19. Montpetit, J., Vivancos, J., Mitani-Ueno, N., Yamaji, N., Rémus-Borel, W. Belzile, F., Ma, J. F., and Bélanger, R. R. 2012. Cloning, functional characterization and heterologous expression of TaLsi1, a wheat silicon transporter gene. Plant Mol. Biol. 79:35-46.

20. Reidinger, S., Ramsey, M. H., and Hartley, S. E. 2012. Rapid and accurate analyses of silicon and phosphorus in plants using a portable X-ray fluorescence spectrometer. New Phytol. 195:699-706.

21. Shanner, G., and Finney, R. E. 1977. The effect of nitrogen fertilization on the expression of slow-mildewing resistance in Knox wheat. Phytopathology 67:1051-1056.

22. Sugimoto, T., Kato, M., Yoshida, S., Matsumoto, I., Kobayashi, T., Kaga, A., Hajika, M., Yamamoto, R., Watanabe, K., Aino, M., Matoh, T., Walker D. R., Biggs A. R., and Ishimoto, M. 2012. Pathogenic diversity of Phytophthora sojae and breeding strategies to develop Phytophthora-resistant soybeans. Breed. Sci. 61:511-522.

23. Tyler, B. M. 2007. Phytophthora sojae: Root rot pathogen of soybean and model oomycete. Mol. Plant Pathol. 8:1-8. 